\title{
COMPORTAMENTO DE CONSUMIDORES E CARACTERÍSTICAS NO DESCARTE DE EQUIPAMENTOS ELETRÔNICOS EM BAIRRO RESIDENCIAL DE BELÉM - PARÁ
}

\author{
Edwin Hennington Pereira Malheiros \\ Mestrando no Programa de Pós-Graduação em Desenvolvimento e Meio Ambiente Urbano \\ pela Universidade da Amazônia (UNAMA), Pará, Brasil \\ edwinhpm@gmail.com
}

Analaura Corradi Doutora em Ciências Agrárias em Agroecosistemas Amazônicos pela Universidade Federal Rural da Amazônia (UFRA), Pará, Brasil corradi7@gmail.com

Douglas Junio Fernandes Assumpção Pós-Doutorado em Comunicação, Linguagens e Cultura pela Universidade da Amazônia (UNAMA), Pará, Brasil rp.douglas@hotmail.com

\section{RESUMO}

O consumo de equipamentos eletrônicos cresce constantemente a cada ano no país, segundo informações de consultorias como a Fundação Getúlio Vargas e a Growth from Knowledge, seguindo a tendência global. O consumo excessivo combinado com a falta de prática de descarte dos resíduos de equipamentos eletrônicos de forma adequada causa cenários de riscos de impactos ambientais em todo o território nacional. A falta de conhecimento, estrutura e gestão pública em relação ao descarte de equipamentos eletrônicos provocam dúvidas sobre qual o limite suportado pelo meio ambiente em receber os resíduos eletrônicos que, na maioria, são contaminantes e degradam o meio ambiente e a saúde humana devido à presença de agentes químicos. A revisão bibliográfica centra-se nos autores que abordam o comportamento do consumidor. Além do embasamento teórico, a pesquisa foi fomentada com dados referentes ao comércio de produtos eletrônicos no Brasil e os impactos ambientais causados pelo descarte irregular dos resíduos de equipamentos eletrônicos. O objetivo da pesquisa foi identificar o comportamento do consumidor e o descarte de equipamentos eletrônicos e a relação com os impactos ambientais, utilizando parâmetros avaliativos para os respectivos cenários. Para isso, elaborou-se um questionário a fim de sondar e obter dados reais do comportamento do consumidor. O questionário foi destinado a um público de forma generalizada, com recorte, de forma eletrônica. Obtiveram-se respostas de 83 entrevistados de um bairro residencial de Belém, e como resultado, identificaram-se cenários que auxiliam no desenvolvimento de novas políticas públicas, através da compreensão do comportamento do cidadão e buscando complementar práticas já aplicadas na sociedade.

Palavras-chave: Tendência de consumo. Tecnologia. Resíduos Sólidos. Impactos Ambientais. 


\title{
CONSUMER BEHAVIOR AND CHARACTERISTICS IN DISPOSAL OF ELECTRONIC EQUIPMENT IN RESIDENTIAL NEIGHBORHOOD OF BELÉM - PARÁ
}

\begin{abstract}
The consumption of electronic equipment grows steadily every year in the country, according to information from consultants such as Fundação Getúlio Vargas and The Growth from Knowledge, following the global trend. Excessive consumption combined with the lack of proper disposal of electronic equipment waste causes scenarios of risks of environmental impacts throughout the national territory. The lack of knowledge, structure and public management in relation to the disposal of electronic equipment causes doubts about the limit supported by the environment in receiving electronic waste, which, in the majority, are contaminants and degrade the environment and human health due to the presence chemical agents. The literature review focuses on authors who address consumer behavior. In addition to the theoretical basis, the research was encouraged with data related to the trade of electronic products in Brazil and the environmental impacts caused by the irregular disposal of waste electronic equipment. The objective of the research was to identify the behavior of consumption and disposal of electronic equipment and the relationship with environmental impacts, using evaluation parameters for the respective scenarios. For this, a questionnaire was designed in order to probe and obtain real data on consumer behavior. The questionnaire was aimed at a general public, with a personal cut, electronically. Answers were obtained from 83 interviewees from a residential neighborhood in Belém, and as a result, scenarios were identified that help in the development of new public policies, through the understanding of the citizen's behavior and seeking to complement practices already applied in society.
\end{abstract}

Keywords: Consumer trend. Technology. Solid waste. Environmental impacts. 


\section{INTRODUÇÃO}

A crescente demanda por equipamentos eletrônicos mais modernos e eficientes tem contribuído para o número elevado de resíduos eletrônicos descartados de forma incorreta e gerando assim um problema ambiental grave, pois o acúmulo desse tipo de lixo, sem destinação correta provoca sérios riscos ao meio ambiente e,, em alguns casos esses riscos podem ser irreversíveis (SELPIS; CASTILHOS; ARAÚJO, 2012).

O crescimento dos resíduos eletrônicos é decorrente do avanço tecnológico dos últimos anos, aumentando, significativamente, a quantidade e diversidade dos equipamentos, fazendo com que a população e empresas descartem seus equipamentos com mais frequência, e por isso, eles tornam-se obsoletos mais rapidamente. Estes resíduos hoje têm percentual significativo no lixo descartado ao meio ambiente (SCHONS, 2012). Daí a importância da compreensão do comportamento do consumidor para criar uma melhor gestão de resíduos de Equipamentos Eletrônicos (EE), ou seja, equipamentos que se tornam "obsoletos", "fora de moda" ou não adequados para certas atividades cotidianas.

O que preocupa acerca dessa questão é o fato de o mercado mundial de produtos eletrônicos continuar em plena ascensão. Cada dia novos produtos são lançados e cada vez mais as pessoas se sentem seduzidas pelas novas tecnologias, fazendo a troca de seus produtos numa frequência maior (ABINEE, 2010).

Segundo Andrade, Fonseca e Mattos, o século XXI é marcado pelo alto consumo de produtos eletrônicos. Sob o enfoque econômico e a pretensão de facilitar o cotidiano humano, os produtos eletrônicos, como computadores e celulares, estão cada vez mais presentes no cotidiano das pessoas e possuem o condão de tornarem a sociedade moderna dependente desses equipamentos, fazendo-a acreditar que a vida sem eles seria muito difícil (ANDRADE; FONSECA; MATTOS, 2010).

Devido às crescentes inovações tecnológicas, em que produtos se tornam obsoletos em um prazo cada vez mais curto e a cultura consumista que está se propagando entre os consumidores, o montante de lixo eletrônico gerado está aumentando e causando grandes danos ambientais. Esse tema é uma preocupação relativamente recente, e poucos estudos abordam essa problemática (ANDRADE; FONSECA; MATTOS, 2010).

Como parâmetro, de acordo com a Agência Nacional de Telecomunicações (ANATEL), no mês de junho de 2006, havia 93 milhões de linhas telefônicas celulares ativos no país. 
Segundo pesquisa da FGV/SP, em 2006, haviam instalados no país aproximadamente 32 milhões de computadores. (RODRIGUES, 2012).

Em 2006, segundo Gutierrez, havia aproximadamente 65 milhões de televisores instalados. De acordo com a Meirelles (2020), em pesquisa realizada, em dezembro de 2019, o país apresentava um total aproximado de 264 milhões de aparelhos celulares, 180 milhões de computadores e 250 milhões de vendidos 48 televisores.

Também segundo a mesma fonte, são 424 milhões de dispositivos digitais em uso no Brasil em junho de 2020, sendo 190 milhões de computadores e 234 milhões de smartphones. A densidade (per capita) de dispositivos digitais era de 50\% em 2010, e atinge $200 \%$ em 2020, ou melhor, dois dispositivos digitais por habitante. O que representa um aumento significativo destes equipamentos em circulação na atualidade (MEIRELLES, 2020).

Os dados do crescimento no consumo de EE ilustram o potencial de geração de resíduos que estes equipamentos podem ter. Conhecer como as pessoas descartam seus produtos eletrônicos, qual é o seu entendimento acerca desse problema, se possuem consciência dos danos que o descarte inadequado pode ocasionar e quais são suas expectativas quanto ao descarte são elementos fundamentais para o Governo direcionar melhor suas políticas públicas e para as empresas direcionarem suas ações de forma mais eficaz no combate ao lixo eletrônico.

Justifica-se esta pesquisa devido ao crescimento significativo na aquisição de EE no Brasil, gerando um potencial crescimento de resíduos contaminantes diante da precariedade do atual cenário de coleta de resíduos sólidos urbanos.

Esta pesquisa tem como objetivo geral identificar o comportamento do consumo e descarte de EE relacionados com os impactos ambientais, utilizando parâmetros avaliativos para os respectivos cenários. Como objetivos específicos têm-se: (i) analisar a tendência de consumo dos equipamentos eletrônicos e o tempo de utilização dos mesmos; (ii) analisar a tendência de destinação e as possíveis consequências ao meio ambiente. Assim, contribuindo com informações para melhor estruturar as políticas públicas ambientais. 


\section{COMPORTAMENTO DO CONSUMIDOR E AS INFLUÊNCIAS}

Considerando que o ser humano, enquanto indivíduo consumidor tem seu comportamento de consumo influenciado a todo tempo, o processo de consumo é composto por questões que influenciam o consumidor antes, durante e após a compra (SOLOMON, 2002).

Statt (1997) afirma que o comportamento do consumidor consiste nas atividades mentais, emocionais e físicas que motivam as pessoas quando selecionam, compram, usam e descartam produtos e serviços para satisfazerem suas necessidades e desejos.

Baseado na definição de Statt, Arnould, Price e Zinkhan (2004) que propuseram um modelo do ciclo de consumo, ilustrado na figura 1:

Figura 1 - Ciclo de Consumo

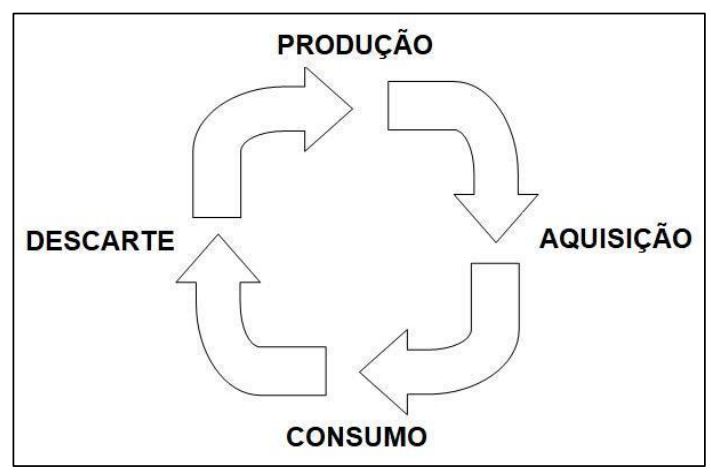

Fonte: adaptado de Statt, Arnoud, Price e Zinkhan (MALHEIROS, CORRADI E ASSUMPÇÃO, 2020).

Segundo Mowen e Minor (2005), o estudo do comportamento do consumidor é essencial para o entendimento das preferências dos consumidores. A compreensão do processo de consumo proporciona benefícios para as empresas na tomada de decisões, para os legisladores e controladores na criação de leis, para os pesquisadores ao fornecer base de conhecimento para a análise dos consumidores, além de ajudar a compreender os fatores sociais que influenciam o comportamento humano.

Ao tratar das questões relacionadas ao consumo, Bauman (2008) sustenta que o consumo não está relacionado apenas à aquisição de produtos, mas a hábitos, valores e aparências. 
Assim, Bauman (2008) diz que na sociedade de consumo, ninguém pode se tornar sujeito antes de se tornar mercadoria, seja pela posse de objetos de consumo desejáveis, ou pela sua própria transformação em padrões socialmente mais aceitos e destacáveis.

Para o autor supracitado, a questão central da sociedade de consumo está ligada ao desejo, que remeta a ideia de insaciabilidade, de modo que são efêmeros, evasivos, voláteis e perpétuos.

Segundo Schiffman e Kanuk (2000), os pesquisadores dos consumidores estão interessados em como os indivíduos descartam seus produtos usados, levando em consideração que o descarte de resíduos sólidos se tornou um grande problema ambiental que as empresas devem levar em consideração ao desenvolver novos produtos ou embalagens.

\begin{abstract}
Guimarães (2011, p. 111) afirma "que o consumo deve ser feito com responsabilidade e consciência diante das consequências socioambientais, reduzindo a intensidade material como fator essencial ao desenvolvimento econômico e evitando o desperdício e a poluição de recursos naturais".

"A geração de resíduos sólidos está diretamente ligada aos padrões culturais, renda e hábitos de consumo da sociedade, sendo este último uma das principais causas da grande quantidade de resíduos, resultado de uma sociedade que transforma supérfluos em necessidades por meio de um consumo desmedido". (ROTH e GARCIAS 2008, p. 9),
\end{abstract}

Mészáros (2011) diz que a lógica da expansão do capital induz a uma série de contradições, sendo uma delas o crescimento da produção a todo custo, com a consequente destruição ambiental.

\begin{abstract}
A "sociedade dos descartáveis" encontra equilíbrio entre a produção e consumo, necessário para sua contínua reprodução, somente se ela puder "consumir" artificialmente e em grande velocidade (isto é descartar prematuramente) imensas quantidades de mercadorias, que anteriormente pertenciam à categoria de bens relativamente duráveis. Desse modo, a sociedade se mantém como um sistema produtivo manipulado a aquisição dos chamados "bens de consumo duráveis", que necessariamente são lançados ao lixo muito antes de esgotada sua vida útil (MÉSZÁROS, 2011, p. 640).
\end{abstract}

A tendência de redução da vida útil das mercadorias acelera o ciclo reprodutivo do capital, ou seja, quanto menos uma mercadoria é usada ou reutilizada, melhor, uma vez que a subutilização implica novas vendas. Novas vendas implicam mais produtos a serem descartados. 
O decréscimo do tempo de utilização cria a demanda por outro produto e este é o principal mecanismo pelo qual o capital vem atingindo um crescimento imensurável ao longo da história. Esse crescimento econômico é refletido no meio ambiente. (MÉSZÁROS, 2011).

É necessário investir em educação ambiental como forma de sensibilizar e conscientizar a sociedade para hábitos mais pensados com relação ao seu padrão ideal de consumo e, consequentemente, com relação aos resíduos sólidos gerados, orientando o indivíduo para o exercício de sua cidadania ambiental (ARANCIBIA, 2012; ROTH; GARCIAS, 2008).

Segundo Ahmed e Coutinho (2009), repensar o consumo passa ter importância ao passo que nossa Constituição determina que é dever de todos zelar pela qualidade de vida da presente e futuras gerações. Portanto, torna-se imprescindível pensar o fenômeno da sociedade de consumo e a cultura do descartável, do desperdício, desenvolvendo mecanismos no processo de compra e descarte, que minimizem os impactos ambientais.

Assim, Ortiz (2011) destaca que a:

preocupação da sociedade com o meio ambiente é o primeiro passo para modificar hábitos de consumo que promovam a redução na produção de resíduos sólidos ${ }^{1}$, o melhor aproveitamento dos recursos existentes e a capacidade de reconhecer, recolher e separar os materiais passíveis de reciclagem (ORTIZ, 2011, p. 34).

Além das características do consumidor apresentadas por Ortiz (2011) e Arancibia (2012), no cenário atual de Pandemia² de acordo com a consultoria Growth From Knowledge $\left(\mathrm{GFK}^{3}\right)$, parte dos brasileiros passou a trabalhar dentro de casa tendo que utilizar computadores pessoais e aparelhos celulares compatíveis com transmissões ao vivo. Além disso, do ensino infantil às universidades, começaram a ter as aulas transmitidas e compartilhadas pela internet.

\footnotetext{
${ }^{1}$ Pesquisa realizada pela Synovate em 11 capitais brasileiras indicou que são jogadas fora, anualmente, cerca de 12 bilhões de sacolas plásticas, sem manejo adequado, que causam visíveis estragos no meio ambiente urbano e na natureza. Dos 1.100 entrevistados, 40\% deles disseram que estariam dispostos pessoalmente a não usar sacolas plásticas. Synovate, Wal Mart Brasil e Ministério do Meio Ambiente. Sustentabilidade aqui e agora: brasileiros de 11 capitais falam sobre meio ambiente, hábitos de consumo e reciclagem. 2010. Disponível em: http://www.globalgarbage.org/sustentabilidade_aqui_agora_182.pdf. Acesso em: 03 fev. 2021.

2 Organização Pan-Americana de Saúde (OPAS) - A pandemia de COVID-19 é uma pandemia em curso de COVID-19, uma doença respiratória aguda causada pelo coronavírus da síndrome respiratória aguda grave 2 (SARS-CoV-2) - https://www.paho.org/pt/covid19

${ }^{3}$ GFK - Growth From Knowledge - Empresa de consultoria fundada em 1934, especializada em estudos sobre consumo global.
} 
Devido a isso, a procura por equipamentos cresceu rapidamente nos últimos meses de 2020 . Segundo a mesma consultoria, no ano de 2020 , a venda de notebooks cresceu $173 \%$ desde março. A de tablets, 176\%. A venda de televisores e celulares, que estavam em queda até o mês de fevereiro, subiram $126 \%$ e $125 \%$, respectivamente.

Como consequências do aumento da produção de EE e o consumo excessivo desses produtos têm-se: o aumento do descarte de resíduos de equipamentos eletrônicos e a complexidade do gerenciamento destes resíduos, resultando em disparidade entre descarte e gerenciamento, causando impactos socioambientais.

Diante do cenário de crescimento das vendas de produtos eletrônicos descritos anteriormente, observa-se a necessidade permanente de compreender como a sociedade atua no mecanismo de destinação adequada dos resíduos gerados pelo uso destes equipamentos no pós-consumo.

Após a destruição de equipamentos eletrônicos, como por exemplo, interruptor de circuito eletrônico, poderá ocorrer o vazamento do mercúrio, que irá se infiltrar no solo e causar danos ambientais e à população. Esta situação é muito pior nos velhos e menos controlados aterros sanitários, que acabam sendo a maioria em todo país. (GONÇALVES, 2007).

Em relação ao perigo do lixo eletrônico descartado em aterros sanitários, por mais seguros e modernos que sejam os aterros sanitários correm o risco de vazamento de produtos químicos e metais que poderão se infiltrar no solo.

Por volta dos anos de 1960 começaram a surgir iniciativas voltadas às questões ambientais, com o aumento da preocupação com o meio ambiente, buscando protegê-lo de impactos ambientais causados pelo crescimento industrial e de produtos industrializados e os impactos causados devido à produção e ao descarte desses materiais.

Vale ressaltar a criação da Lei de Política Ambiental Americana (National Environmental Policy Act - NEPA, EUA) em 1969. Desde então, diversas conferências mundiais ocorreram com o intuito de discutir políticas de conservação do meio ambiente.

Em 1992, no Brasil, a Conferência Rio-92, onde se reuniram 175 países para tratar de assuntos sobre Mudanças do Clima, as Convenções sobre a Biodiversidade e a Declaração sobre Florestas - além de outros encontros e discussões relacionadas à proteção do meio 
ambiente - fizeram com que fossem adotadas medidas de minimizar os impactos ambientais causados pelo descarte inadequado de resíduos no meio ambiente.

Até as primeiras conferências globais e iniciativas de discussão a respeito dos impactos ambientais e o futuro do planeta, difundia-se a ideia de que apenas ações de redução do crescimento da população e das atividades industriais, relativas ao consumo de recursos naturais, impediriam uma catástrofe global.

É importante fomentar a atenção à cultura do consumo e do desperdício, observando a necessidade de minimizar os resíduos, de acordo com o princípio dos 3Rs - Reduzir, Reutilizar e Reciclar. Pois, ao reduzir, reutilizar e reciclar os resíduos evita-se o desperdício de matéria-prima, assim como se reduz também a quantidade de rejeitos gerados (GUIMARÃES, 2011; PIVA, 2008).

No Brasil, a Lei no 12.305/10, que institui a Política Nacional de Resíduos Sólidos (PNRS), apresenta instrumentos importantes para permitir o avanço necessário do País no embate dos principais problemas ambientais, sociais e econômicos decorrentes do manejo inadequado dos resíduos sólidos (BRASIL, 2010).

Esta política contempla os princípios, as diretrizes, os objetivos, as metas, as ações e os instrumentos que seguidos pela União isoladamente ou em parceria com os estados, o distrito federal, os municípios, bem como a sociedade, apontam para a gestão integrada e ao gerenciamento adequado dos resíduos sólidos.

Atualmente, existem, segundo o governo federal, no ano de 2019, 173 pontos de coleta de eletroeletrônicos no Brasil. Em de Belém, há somente duas empresas que fazem coleta deste tipo de resíduo.

Segundo a Agência Brasil ${ }^{4}$, do governo federal, em fevereiro de 2020, foi assinado o decreto, de no 10.240/2020, pelo presidente da república que regulamenta a logística reversa de produtos eletrônicos, obrigando as empresas do setor a implantarem sistemas de coleta desse tipo de resíduo e dar sua destinação correta. O acordo, agora regulamentado por este decreto, prevê que esse número aumente para 5 mil pontos até 2025, abrangendo os 400 maiores municípios do país, com mais de 80 mil habitantes, e que representam, no total, $60 \%$ da população brasileira.

\footnotetext{
${ }^{4}$ Veículo de Comunicação da Empresa Brasil de Comunicação, uma empresa federal pública criada pela Lei no 11.652/2008.
} 
Segundo o Ministério do Meio Ambiente (BRASIL, 2020), 60\% da população brasileira, que, ao final de 2025, vai ser contemplado, representa uma parcela muito significativa dos resíduos de eletroeletrônicos que temos no Brasil.

\section{MATERIAL E MÉTODOS}

Como metodologia, tem-se revisão bibliográfica e sondagem através de formulário analítico referente ao comportamento do consumidor em relação à aquisição e ao descarte de $\mathrm{EE}$, no município de Belém no ano de 2020, onde foram apresentados dados por meio de gráficos e as relações entre estes. Foi utilizado um recorte de 83 pessoas, com livre distribuição dos formulários por meio eletrônico no bairro da Pedreira, segundo mais populoso do município de Belém, localizado em um dos maiores centros populacionais da do município, segundo informações da Prefeitura, 2011.

No primeiro tópico serão analisados os dados referentes aos índices de consumo de EE no Brasil.

No segundo tópico, será abordada a questão do comportamento do consumidor em relação ao crescimento tecnológico. Como descrito por Andrade, Fonseca e Mattos (2010), sob a pretensão de facilitar o dia a dia, os produtos eletrônicos, como computadores e celulares, estão cada vez mais presentes no cotidiano das pessoas e possuem a capacidade de tornarem a sociedade moderna dependente desses equipamentos, fazendo-a acreditar que a vida sem eles seria muito difícil.

No terceiro tópico, serão abordadas informações acerca dos impactos ambientais provenientes do descarte irregular dos resíduos de EE e o papel da sociedade diante deste cenário.

Suarez et al. (2010) defendem que a realização de pesquisas sobre o descarte de produtos permite compreender o conceito de marketing de forma mais sistêmica e entender como o destino que é dado aos produtos pode impactar as decisões tomadas pelo consumidor no momento da compra.

Ao final serão analisados os dados referentes ao questionário elaborado, identificando possíveis cenários de comportamento de consumo e descarte de EE. 
COMPORTAMENTO DE CONSUMIDORES E

CARACTERÍSTICAS NO DESCARTE DE EQUIPAMENTOS

ELETRÔNICOS EM BAIRRO RESIDENCIAL DE BELÉM - PARÁ
Edwin Hennington Pereira Malheiros

Analaura Corradi

Douglas Junior Fernandes Assumpção

\section{ANÁLISE DOS DADOS E RESULTADOS}

Baseado nos resultados, foi possível identificar como o consumidor realiza o descarte destes equipamentos e analisar as expectativas do consumidor quanto às possibilidades de descarte, contribuindo com novas formas de gestão deste tipo de resíduo contaminante.

Os indivíduos envolvidos neste formulário foram sondados no período de 1 으 a $30 \mathrm{de}$ junho de 2020, via plataforma Forms ${ }^{5}$ do Google, e são de recorte de um determinado bairro residencial - consumidores comuns do bairro da Pedreira, que segundo o IBGE (2010) é o segundo bairro mais populoso do município de Belém. Ao final obtiveram-se respostas de 83 indivíduos com faixas etárias diversas, 16,9\% têm entre 20 e 29 anos, 38,6\% têm entre 30 e 39 anos, 18,1\% têm entre 40 e 49 anos, 26,5\% têm mais de 50 anos de idade. Do total, 50,6\% são do sexo masculino e $49,4 \%$ são do sexo feminino. A maioria possui filhos, correspondente a $72 \%$ dos envolvidos.

Gráfico 1 - Porcentagem referente a faixa etária.

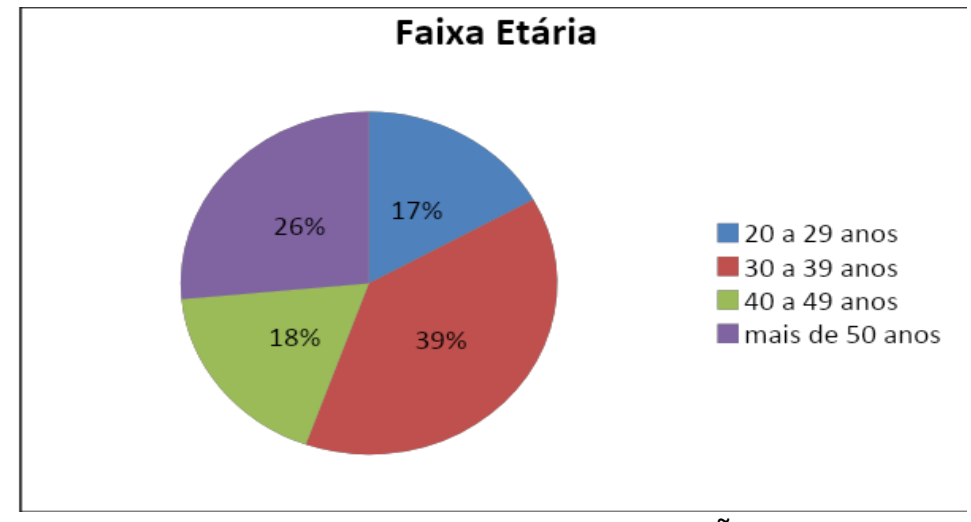

Fonte: MALHEIROS, CORRADI E ASSUMPÇÃO (2020)

\footnotetext{
${ }^{5} \mathrm{O}$ Google Forms é um serviço gratuito para criar formulários online.
} 
Gráfico 2 - Porcentagem referente ao sexo do entrevistado.

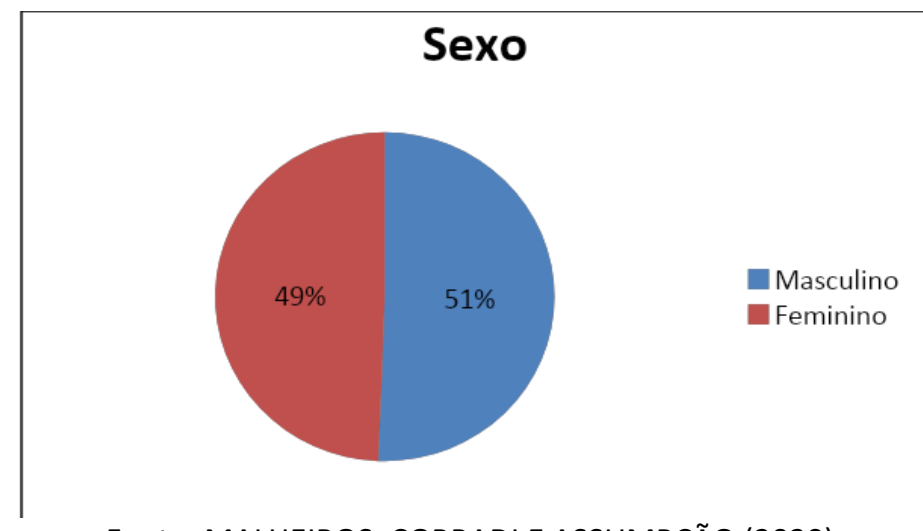

Fonte: MALHEIROS, CORRADI E ASSUMPÇÃO (2020)

Sobre a renda familiar mensal, obteve-se um total de $16,9 \%$ com renda entre $R \$ 1.500,00$ a $R \$ 2.500,00,14,5 \%$ com renda entre $R \$ 2.501,00$ a $R \$ 4.500,00,38,6 \%$ com renda entre $R \$ 4.501,00$ a $R \$ 10.000,00$ e 30,1\% com renda acima dos $R \$ 10.000,00$. Considerando os dados da pesquisa, tem-se um cenário, no qual $68,7 \%$ possuem renda entre $R \$ 4.501,00$ e a mais de $\mathrm{R} \$ 10.000,00$. Segundo o IBGE ${ }^{6}$, a renda familiar mensal do brasileiro em 2018 foi de $\mathrm{R} \$ 5.436,70$, proporcional ao identificado na pesquisa.

Gráfico 3 - Porcentagem da Renda Mensal Familiar.

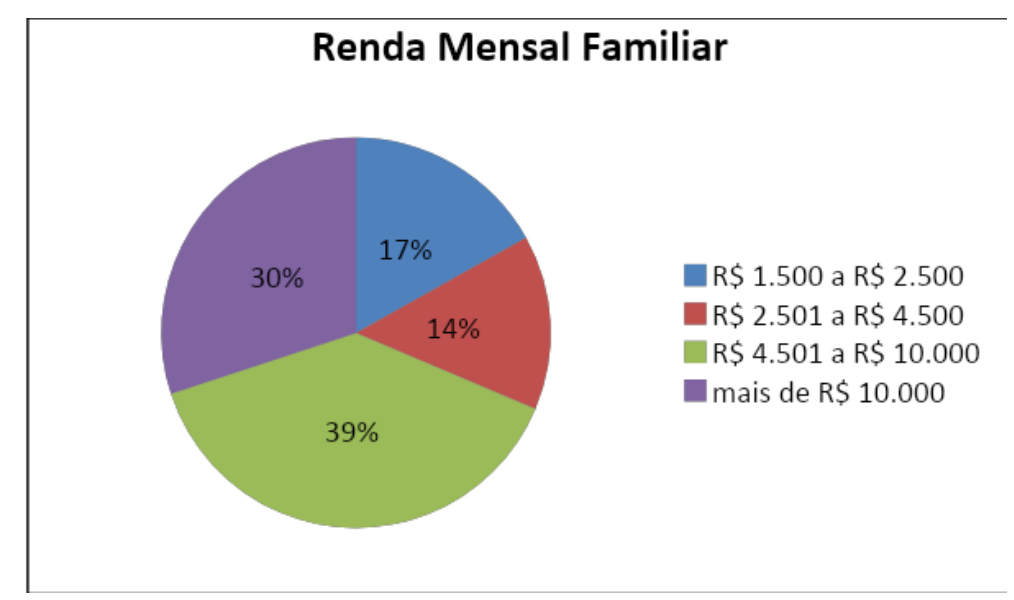

Fonte: MALHEIROS, CORRADI E ASSUMPÇÃO (2020)

A pesquisa focou nos três principais produtos eletrônicos de consumo brasileiro: televisores, computadores e aparelhos celulares. Diante disto, verificou-se a quantidade de

\footnotetext{
${ }^{6}$ Instituto Brasileiro de Geografia e Estatística.
} 
produtos, frequência de consumo, comportamento de descarte e conhecimento sobre as formas de descarte e os impactos ambientais relacionados a este descarte.

Sobre os televisores, obtive-se o resultado de que mais da metade dos entrevistados, 73,5\%, possuem até 03 (três) televisores em suas residências e que a maioria substitui os equipamentos a cada 05 (cinco) anos ou mais.

Gráfico 4 - Porcentagem de televisores nas residências.

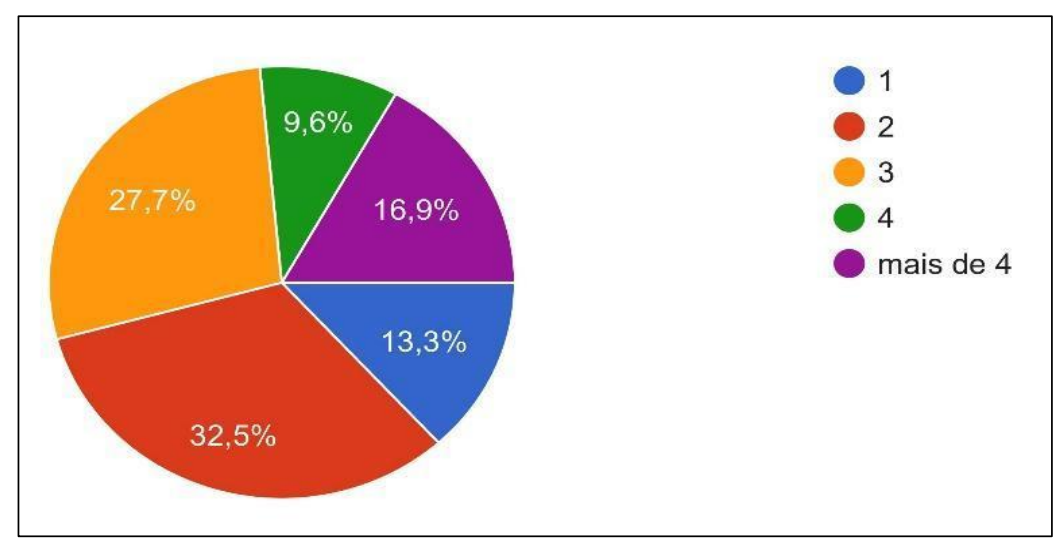

Fonte: MALHEIROS, CORRADI E ASSUMPÇÃO (2020)

Sobre os computadores - ou notebooks - $67 \%$ responderam possuir 01 (um) ou 02 (dois) equipamentos do tipo em sua residência, e que a maioria, $72 \%$ adquire um novo equipamento a cada 4 anos ou mais.

Gráfico 5 - Porcentagem de computadores nas residências.

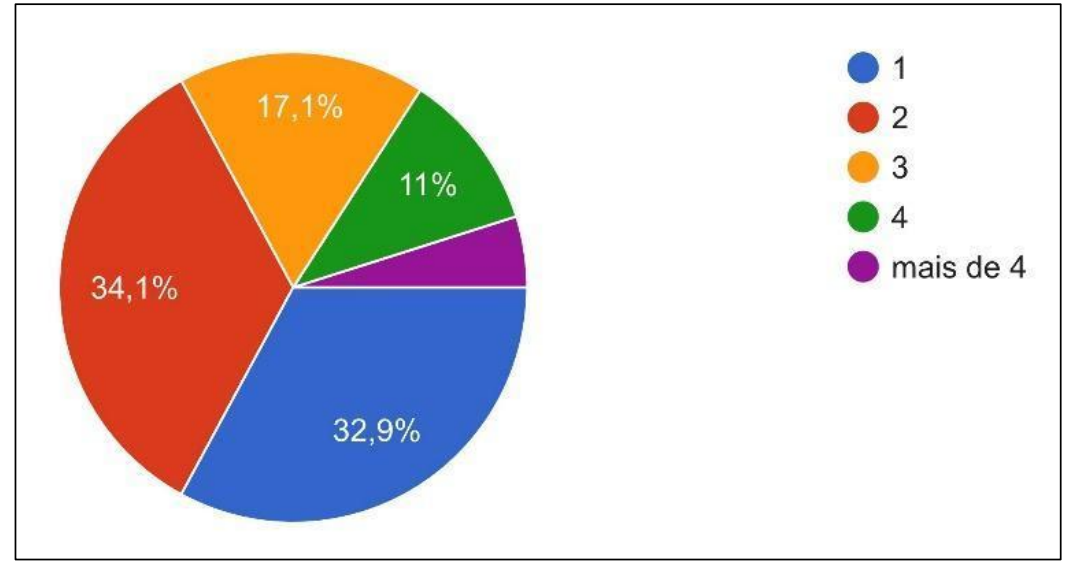

Fonte: MALHEIROS, CORRADI E ASSUMPÇÃO (2020) 
Sobre os aparelhos celulares, $71,1 \%$ responderam possuir pelo menos 04 aparelhos em sua residência e 28,9\% possuem mais de 04 aparelhos. $27,7 \%$ dos entrevistados responderam que adquirem um novo equipamento a cada ano, 26,5\% a cada 02 anos, $25,3 \%$ a cada 03 anos e os demais, $20,5 \%$ após 04 anos ou mais de uso. 0 interessante foi que a maioria, $56,6 \%$ dos entrevistados descarta os equipamentos sem utilidade entre 02 a 05 anos após adquirirem e 30,1\% em menos de 02 anos.

Gráfico 6 - Porcentagem de aparelhos celulares.

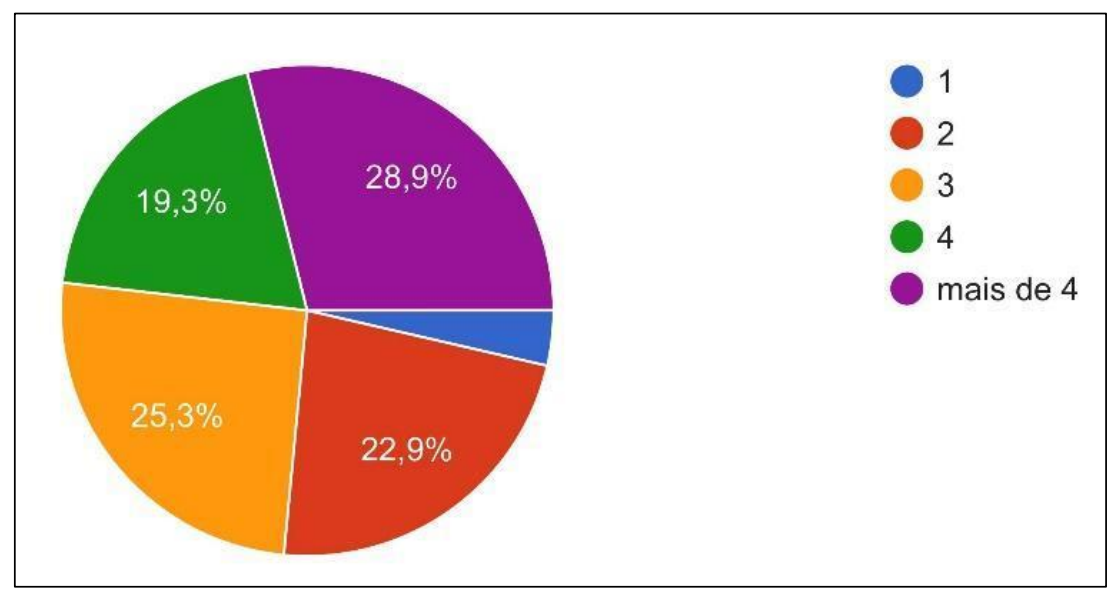

Fonte: MALHEIROS, CORRADI E ASSUMPÇÃO (2020).

Quando questionados sobre o conhecimento de local adequado para recebimento dos eletrônicos que não estejam mais em funcionamento ou sem utilidade, $91,5 \%$ responderam desconhecer. O que indica que há probabilidade de o destino de parte desses equipamentos serem aterros sanitários ou até mesmo descartados em locais desconhecidos, uma vez que $9 \%$ responderam que descartam em lixo comum, sem nenhum tratamento.

Do total, $45 \%$ responderam que quando os equipamentos sofrem danos são encaminhados a assistências técnicas para reparos e posterior utilização e $43 \%$ responderam que deixam guardados em local da residência, pois não sabem o que fazer com o equipamento. Somente $3 \%$ levam a alguma central de coleta de resíduos para de alguma forma dar destino adequado ao resíduo.

Sobre o que os entrevistados achavam que poderia ser feito com os equipamentos sem utilidade, a maioria, 44,91\%, respondeu que os equipamentos deveriam ser coletados, separados e destinados a local específico de tratamento, 37,28\% sugeriram oferecer o equipamento sem utilidade como forma de "entrada" na aquisição de outro equipamento 
similar, assim forçando o retorno do equipamento ao local de venda inicial, $14,40 \%$ acham que os equipamentos sem utilidade deveriam ser doados para reutilização e 3,41\% não vê problema algum descartar como lixo comum a aterros e lixões.

De forma a compreender os níveis de consumo dos produtos e a analisar possíveis "lacunas" de informação da sociedade e da gestão pública, assim contribuindo para criar políticas adequadas e que tornem possível a destinação correta dos resíduos provenientes dos EE não utilizados, observou-se e fez-se comparação entre alguns resultados.

Ao analisar a relação de quantidade de equipamentos, nota-se que a quantidade de aparelhos celulares está equivalente a quantidade de televisores e ambos superam a quantidade de computadores, porém a substituição e descarte dos equipamentos difere na frequência, em que os aparelhos celulares são substituídos muito mais rápido que televisores e computadores. Ou seja, mais aparelhos celulares devem ser adquiridos e outros descartados nos próximos anos que televisores e computadores.

Sobre o conhecimento dos locais de destinação adequada dos equipamentos sem utilidade por parte dos entrevistados, notou-se expressiva quantidade dos que não conhecem nenhum local, representando 91,5\% (Gráfico 7).

Gráfico 7 - Porcentagem do conhecimento acerca de locais de destinação adequados.

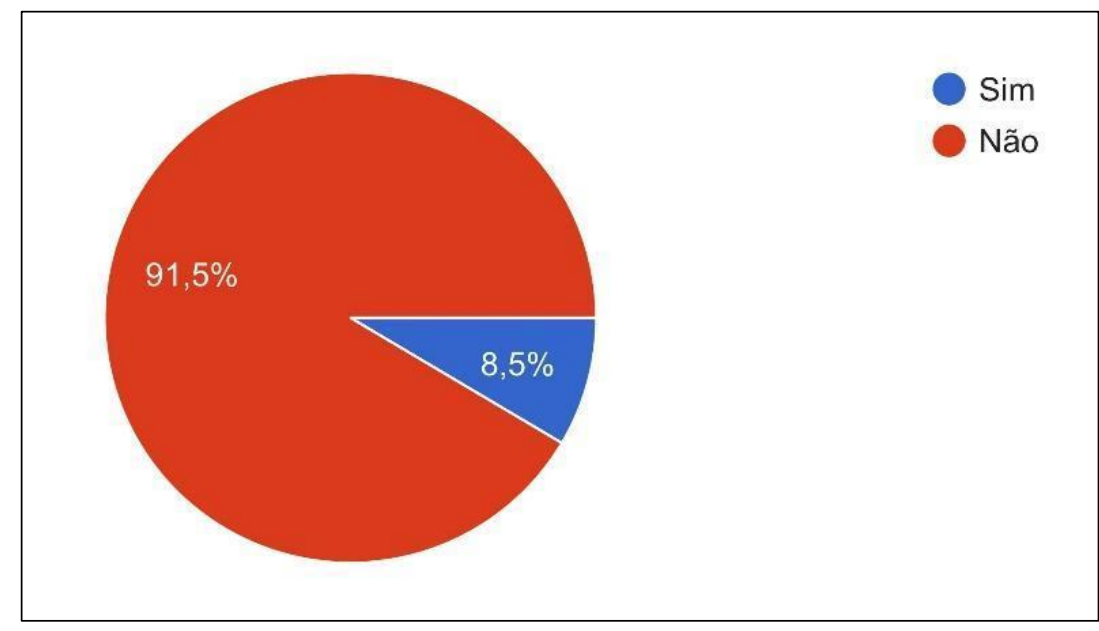

Fonte: MALHEIROS, CORRADI E ASSUMPÇÃO (2020)

Como resposta ao conhecimento dos riscos ambientais causados pelo descarte irregular de equipamentos eletrônicos, obteve-se $87,8 \%$ conhecem os riscos ou parte dos 
riscos causados por este descarte. Somente $12,2 \%$ responderam que não conhecem os riscos causados pelo descarte irregular dos lixos eletrônicos.

Gráfico 8 - Porcentagem do conhecimento acerca dos riscos ambientais.

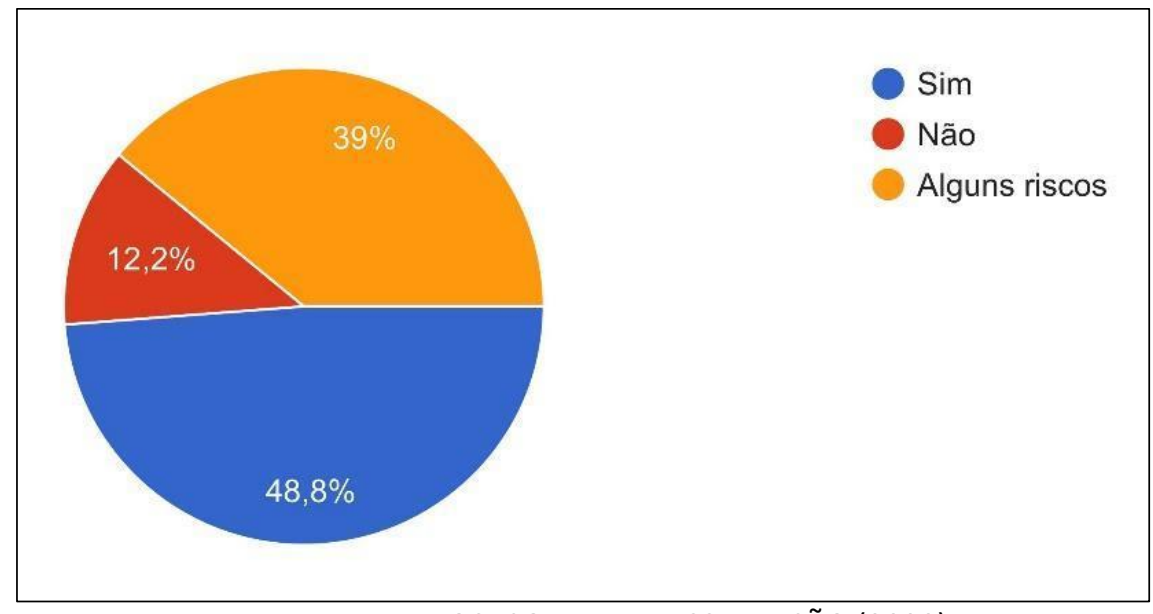

Fonte: MALHEIROS, CORRADI E ASSUMPÇÃO (2020)

Sobre o comportamento do indivíduo quanto ao destino final dos equipamentos pósconsumo, em resposta à pergunta sobre qual a atitude tomada por ele (Gráfico 9), nota-se que $43 \%$ dos entrevistados deixam guardados em sua residência os equipamentos que não tem mais utilidades. Porém, nota-se que $44,9 \%$ esperam poder ter o produto encaminhado a coleta e destinação adequada dos equipamentos eletrônicos (Gráfico 10). Essa relação entre os equipamentos que ficam retidos na residência, com o desejo de se ter locais adequados, é um dos pontos fortes na qualidade de destinação dos equipamentos eletrônicos.

Gráfico 9 - Porcentagem do comportamento após consumo.

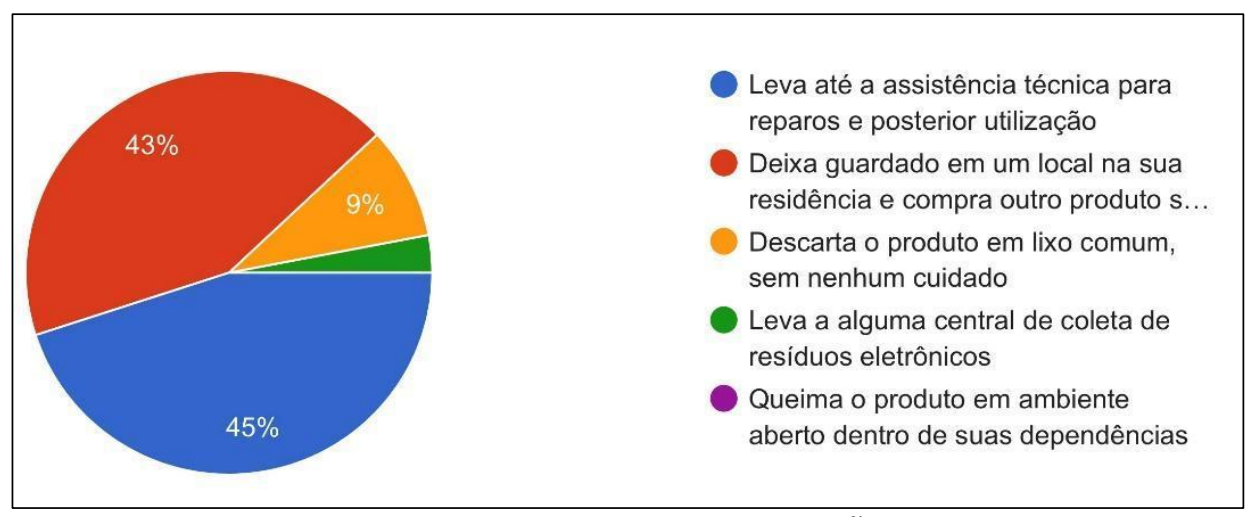

Fonte: MALHEIROS, CORRADI E ASSUMPÇÃO (2020). 
Gráfico 10 - Porcentagem o que gostaria que fosse feito.

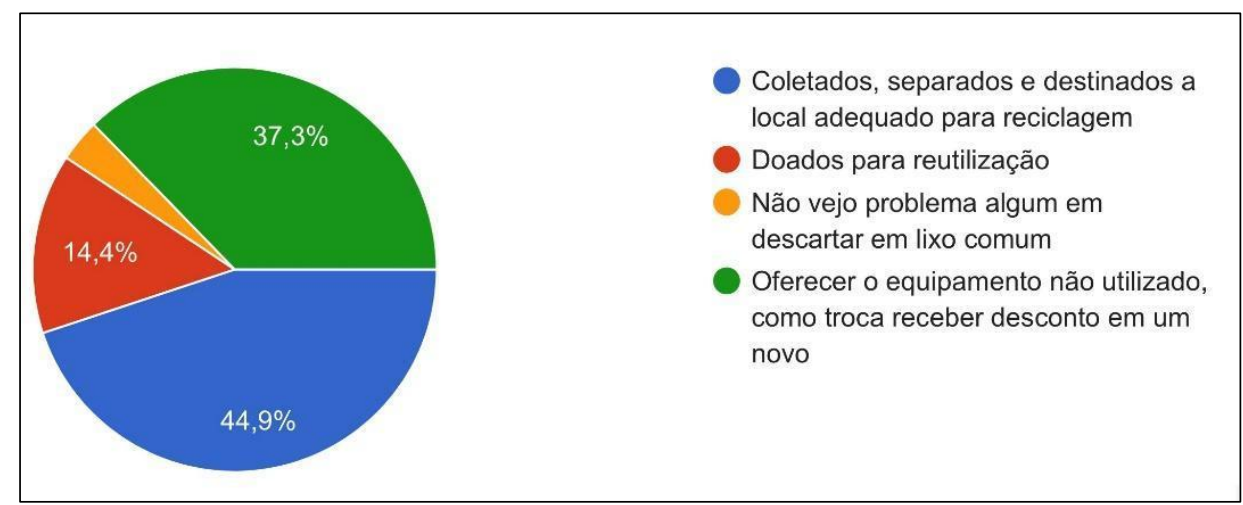

Fonte: MALHEIROS, CORRADI E ASSUMPÇÃO (2020)

\section{CONCLUSÕES}

Conclui-se que por meio da revisão bibliográfica e dos dados referentes aos consumidores relacionados na pesquisa, apresenta-se um aumento no consumo de EE, principalmente de aparelhos celulares; desejo por tratar melhor os resíduos de EE; preocupação com o meio ambiente e os riscos de impactos ambientais que esses equipamentos possam causar; falta de conhecimento acerca de destinação dos resíduos dos equipamentos; acúmulo de EE nos próximos anos cada vez maiores; necessidade de desenvolver políticas públicas aplicadas no sentido de criar locais adequados de recebimento e tratamento destes resíduos e informar melhor a sociedade no município de Belém.

Caso não seja solucionado o problema da informação à sociedade a respeito do descarte adequado, criação de locais de recebimento, tratamento e destinação adequados, possivelmente uma quantidade cada vez maior de resíduos de EE terá como destino lixões e aterros sanitários.

Identificou-se que o perfil do consumidor do bairro pesquisado tem como característica principal um alto consumo e descarte de resíduos de EE, que demonstra a falta de conhecimento acerca de locais de destarte de tais resíduos.

O decreto no 10.240/2020 se apresenta como um marco importante no que diz respeito ao fluxo dos resíduos de equipamentos eletrônicos no país. Porém, os municípios devem identificar o comportamento do consumidor e acompanhar o processo no papel de gestor, concretizando o fluxo desde a aquisição do EE ao descarte de maneira eficiente e segura desses equipamentos. 


\section{REFERÊNCIAS}

ABINEE. Desempenho setorial da indústria eletro e eletrônica. [S. I.: s. n.], 2010.

AHMED, Flávio; COUTINHO, RONALDO. Cidades Sustentáveis no Brasil e sua Tutela Jurídica. Rio de Janeiro: Editora Lumn Juris, 2009.

ANDRADE, R. T. G.; FONSECA, C. S. M.; MATTOS, K. M. C. Geração e destino dos resíduos eletrônicos de informática nas instituições de ensino superior de Natal - RN. HOLOS, Natal, ano 26 , v. 2, p. 100-112, 2010.

ARANCIBIA, F. E. R. Consumo sustentável: padrões de consumo da nova classe média brasileira. 2012. Dissertação (Mestrado em Desenvolvimento Sustentável) - Universidade de Brasília, Brasília, DF, 2012.

ARNOULD, E.; PRICE, L.; ZINKHAN, G. Consumers. 2. ed. New York: McGraw Hill, 2004.

BAUMAN, Zygmunt. Vida para consumo: a transformação das pessoas em mercadorias. Tradução: Carlos Alberto Medeiros. Rio de Janeiro: Zahar, 2008.

BORBA, D. M. Comportamento pós-compra de produtos eletrônicos: uma proposta avaliativa para o descarte de celulares e computadores - Brasília, 2012.

BRASIL. Lei no 12.305, de 2 de agosto de 2010. Institui a Política Nacional de Resíduos Sólidos; altera a Lei no 9.605, de 12 de fevereiro de 1998; e dá outras providências. Brasília, DF: Presidência da República, 2010.

BRASIL. Ministério do Meio Ambiente. Agência Brasil. Decreto no 10.240/2020. Brasília, DF, 2020.

GONÇALVES, A.T. O lado obscuro da high tech na era do neoliberalismo: seu impacto no meio ambiente. In: LIXO Eletrônico. [S. I.], 18 jul. 2007. Disponível em:

http://lixotecnologico.blogspot.com/2007/07/o-lado-obscuro-da-high-tech-na-era-do.html. Acesso em: 25 nov. 2020.

GUIMARÃES, G. C. Consumo Sustentável para Minimização de Resíduos Sólidos. 2011. Dissertação (Mestrado) - Curso de Mestrado em Desenvolvimento Sustentável, Universidade de Brasília - UnB, Brasília, 2011.

MEIRELLES, F. S. Pesquisa Anual do Uso de TI. São Paulo: FGV, 2020. Disponível em: https://eaesp.fgv.br/producao-intelectual/pesquisa-anual-uso-ti. Acesso em: 15 dez. 2020.

MÉSZÁROS, I. Para além do capital: rumo a uma nova teoria da transição. São Paulo: Boitempo Editorial, 2011.

MOWEN, J. C.; MINOR, M. S. Comportamento do Consumidor. São Paulo: Pearson Prentice Hall, 2005. 
ORTIZ, M. A. Responsabilidade pós-consumo e resíduos sólidos na sociedade contemporânea: desafios e limites ao poder econômico. 2011. Dissertação (Mestrado em Direito Político e Econômico) - Universidade Presbiteriana Mackenzie, São Paulo, 2011.

PIVA, A. L. Direito Ambiental, Desenvolvimento Sustentável e Cultura: um enfoque sobre a responsabilidade ambiental pós-consumo. 2008. Dissertação (Mestrado Direito) - Pontifícia Universidade Católica do Paraná, Curitiba, 2008.

RODRIGUES, A. C. Fluxo domiciliar de geração e destinação de resíduos de equipamentos elétricos e eletrônicos no município de São Paulo/SP: caracterização e subsídios para políticas públicas. 2012. São Paulo. Tese (Doutorado em Saúde Pública) - Programa de PósGraduação em Saúde Pública, Universidade de São Paulo, São Paulo, 2012.

ROTH, C.; GARCIAS, C. M. A influência dos padrões de consumo na geração de resíduos sólidos dentro do sistema urbano. REDES, Santa Cruz do Sul, v. 13, n. 3, p. 5 -13, set/dez. 2008.

SELPIS, Adriano Nicolau; CASTILHOS, Renata de Oliveira; ARAÚJO, João Alberto Borges de. Logística reversa de resíduos eletroeletrônicos. Revista Tekhne e Logos, Botucatu, v. 3, n. 2, jul. 2012.

SCHONS, Paula Cristina. O gerenciamento dos resíduos eletroeletrônicos: um estudo sobre as empresas de informática em São Miguel do Oeste. E-tech, Florianópolis, v. 5, n. 1, p. 5688, 2012. Disponível em: https://etech.emnuvens.com.br/edicao01/article/view/277/241. Acesso em: 11 dez. 2020.

SOLOMON, M. R. O comportamento do consumidor: comprando, possuindo e sendo. 5. ed. Porto Alegre: Bookman, 2002.

STATT, D. A. Understanding the consumer: a psychological approach. London: McMillan Press, 1997. Caps. 1 e 3.

SUAREZ, M. C. et al. Oportunidade e desafio em marketing: como e porque as pessoas de desfazem de seus bens? Revista Eletrônica de Administração, Edição 68, v. 17, n. 1, p. 2657, jan/abr 2010.

SCHIFFMAN, L. G.; KANUK, L. L. Comportamento do Consumidor. 6. ed. Rio de Janeiro: Prentice Hall, 2000. 